\title{
Himalayan Fibrillatory Waves in Juvenile Rheumatic Mitral Stenosis
}

\author{
Mohamed Kassim Akheela ${ }^{1} \quad$ A. Shaheer Ahmed ${ }^{2}$ \\ ${ }^{1}$ Department of Anaesthesiology, All India Institute of Medical \\ Sciences, New Delhi, India \\ 2 Department of Cardiology, Vardhman Mahavir Medical College and \\ Safdarjung Hospital, New Delhi, India \\ Ind J Car Dis Wom 2021;6:250-251.
}

\begin{abstract}
Address for correspondence A. Shaheer Ahmed, MD, DM, DNB, Department of Cardiology, 7th Floor, Super Speciality Block, Vardhman Mahavir Medical College and Safdarjung Hospital, New Delhi 110029 (e-mail: ahmedshaheer53@gmail.com).
\end{abstract}

\author{
Abstract \\ Keywords \\ - atrial fibrillation \\ - juvenile mitral \\ stenosis
}

An 18-year-old girl, a known case of rheumatic mitral stenosis, presented with dyspnea and palpitations. Electrocardiogram was done, which revealed atrial fibrillation and a large amplitude atrial fibrillatory wave, which was more than the voltage of $\mathrm{R}$ wave $\mathrm{V} 1$, a finding which is quite uncommon. Echocardiography revealed a large left atrium which was $80 \mathrm{~mm}$ in diameter. The patient was started on oral anticoagulation and referred for mitral valve replacement with maze procedure.

\section{Introduction}

Juvenile mitral stenosis was first described by Dr. Sujoy B. Roy from India. Juvenile mitral stenosis is characterized by presentation with severe mitral stenosis in those less than 20 years of age. Such patients tend to have less calcific valves, severe pulmonary hypertension, and fairly normal cardiac output. Atrial fibrillation (AF) is relatively uncommon, seen in only around $6 \%$ of the cases. We report a case of juvenile mitral stenosis, who presented with Himalayan fibrillatory waves in the electrocardiogram.

\section{Case Presentation}

An 18-year-old girl presented with complaints of dyspnea on exertion, New York Heart Association (NYHA) class II for 4 years, which progressed to class III for the past 1 month. She also had history of intermittent palpitations. On examination, she had a pulse rate of $126 / \mathrm{min}$, which was irregularly irregular. Cardiovascular examination revealed S1 of variable intensity and a middiastolic murmur at the apex. Chest X-ray showed left atrial enlargement. Electrocardiogram showed irregularly irregular rhythm with a ventricular rate of ap- proximately $98 / \mathrm{min}$. There was a coarse atrial fibrillatory waveform seen in the electrocardiograph (ECG). The fibrillatory waves were very large, measuring around 6 to $7 \mathrm{~mm}$. The amplitude of the fibrillatory wave was more than the amplitude of QRS complex in lead V1 ( $\mathbf{- F i g . 1 A}$ ). This feature was suggestive of left atrial enlargement. Echocardiography revealed severe mitral stenosis with mitral valve area of $0.8 \mathrm{~cm}^{2}$ and mild-to-moderate mitral regurgitation. The left atrium was grossly dilated measuring $80 \mathrm{~mm}$ in parasternal

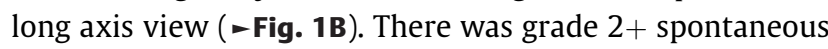
echo contrast in the left atrium. Anticoagulation was initiated with enoxaparin and, subsequently, warfarin. The patient was referred for mitral valve replacement and maze procedure.

\section{Discussion}

AF has an overall prevalence of 1 to $2 \%$ worldwide. ${ }^{1}$ In elderly population, nonvalvular AF predominates, whereas in younger population, it is predominantly due to valvular heart disease. Among the valvular heart disease, mitral stenosis is the most common lesion associated with AF. The presence of $\mathrm{AF}$ in juvenile rheumatic mitral stenosis relatively published online December 14, 2021
DOI https://doi.org/ $10.1055 / \mathrm{s}-0041-1739128$. ISSN 2455-7854.

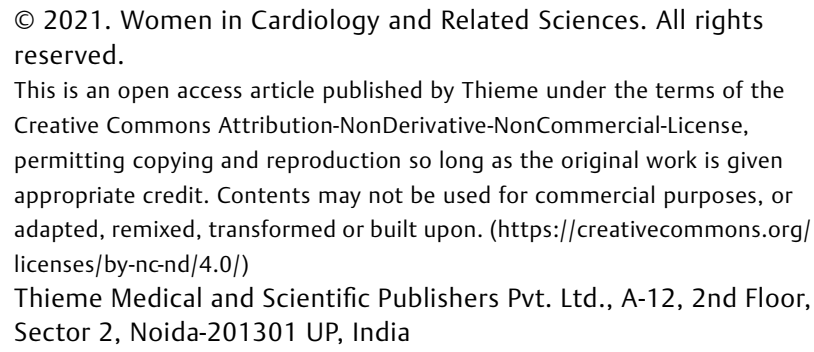

This is an open access article published by Thieme under the terms of the Creative Commons Attribution-NonDerivative-NonCommercial-License, permitting copying and reproduction so long as the original work is given appropriate credit. Contents may not be used for commercial purposes, or adapted, remixed, transformed or built upon. (https://creativecommons.org/ licenses/by-nc-nd/4.0/)

Thieme Medical and Scientific Publishers Pvt. Ltd., A-12, 2nd Floor, Sector 2, Noida-201301 UP, India 


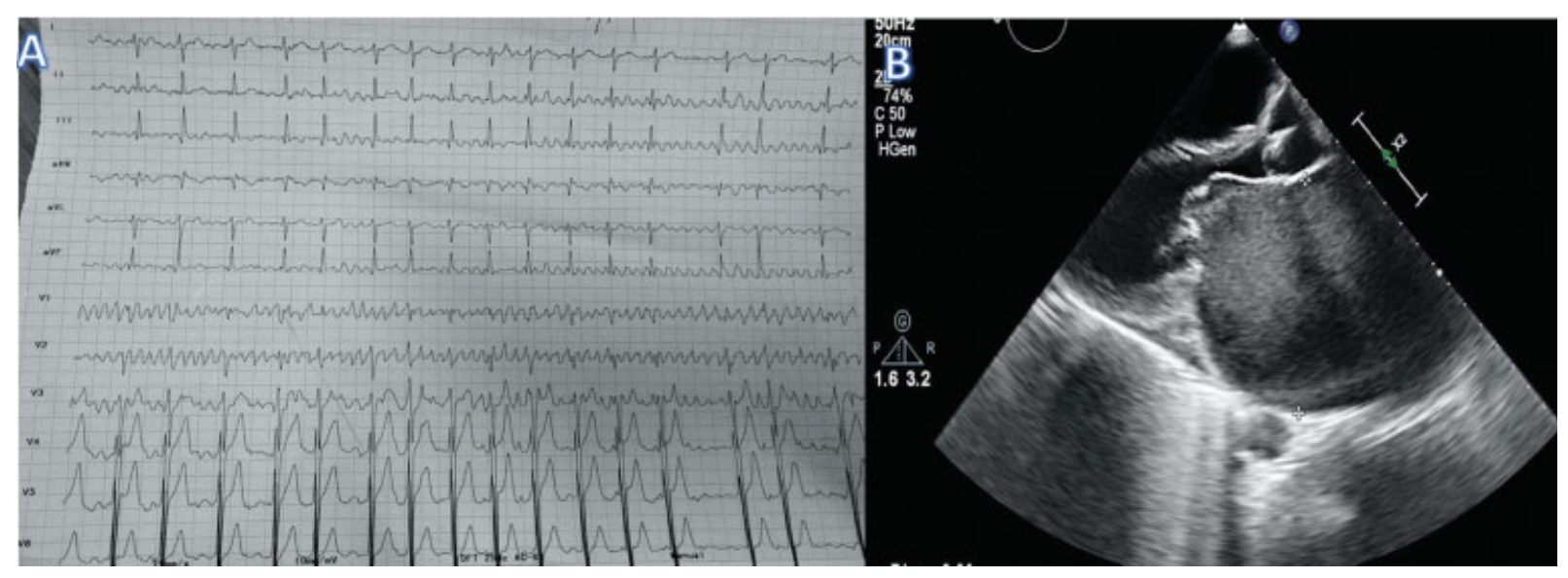

Fig. 1 (A) 12-lead electrocardiogram showing large (Himalayan) fibrillatory waves (B) Echocardiography in parasternal long axis view showing left atrial enlargement, spontaneous echo contrast, and thickened mitral valve.

uncommon, with an incidence of 3 to $10 \%$, which is very less when in comparison with their older counterparts. ${ }^{2}$ Based on the amplitude of the fibrillatory waves, AF is classified as fine $\mathrm{AF}$ if it is less than $1 \mathrm{~mm}$ and coarse $\mathrm{AF}$ if more than $1 \mathrm{~mm}$. Coarse AF is considered as a marker of left atrial enlargement. $^{3}$ Coarse AF is associated with hypertrophied atrial myocardium and more organized left atrial contraction in comparison to fine $\mathrm{AF}^{4}$ Coarse AF has higher propensity for thromboembolic events despite having lesser tendency for clot formation. ${ }^{5}$ Extensive atrial myocardial hypertrophy without much structural damage in this young patient of rheumatic mitral stenosis is the plausible explanation for Himalayan fibrillatory wave. Systematic examination of this electrocardiogram is vital, as looking only at the lead V1 will give impression of either ventricular tachycardia or artifact.

\section{Conclusion}

Juvenile mitral stenosis is less commonly associated with AF. In our case, juvenile mitral stenosis presented
AF, that too with coarse large amplitude atrial fibrillatory waves.

\section{Conflict of Interest}

None declared.

\section{References}

1 Kornej J, Börschel CS, Benjamin EJ, Schnabel RB. Epidemiology of atrial fibrillation in the 21st century: novel methods and new insights. Circ Res 2020;127(01):4-20

2 Roy SB. Proceedings: challenge of juvenile mitral stenosis in India. Jpn Circ J 1975;39(02):198

3 Thurmann M, Janney JG Jr. The diagnostic importance of fibrillatory wave size. Circulation 1962;25:991-994

4 Pourafkari L, Baghbani-Oskouei A, Aslanabadi N, et al. Fine versus coarse atrial fibrillation in rheumatic mitral stenosis: the impact of aging and the clinical significance. Ann Noninvasive Electrocardiol 2018;23(04):e12540

5 Yilmaz MB, Guray Y, Guray U, et al. Fine vs. coarse atrial fibrillation: which one is more risky? Cardiology 2007;107 (03):193-196 